\title{
Zigbee based Wireless Sensing Platform for Monitoring Agriculture Environment
}

\author{
N.Krishna Chaitanya \\ Department of ECE \\ G.V.P.College of Engineering \\ Visakhapatnam, AP, India
}

\author{
G.Anand Kumar \\ Department of ECE \\ G.V.P.College of Engineering \\ Visakhapatnam, AP, India
}

\author{
P.Aruna Kumari \\ Department of ECE \\ G.V.P.College of Engineering \\ Visakhapatnam, AP, India
}

\begin{abstract}
To monitor the agriculture environment a wireless sensor network is developed using Zigbee. Here agriculture monitoring is designed using ARM7 based 16/32-bit Microcontroller which measures the humidity, temperature and content of soil moisture and the measured parameters are displayed on a $16 \times 2 \mathrm{LCD}$, the obtained parameters are transmitted using a Zigbee module. At the receiver side a Zigbee is connected to the system and the received data is displayed in GUI which is designed using VB6.0 and saved in the system data base for further analysis.
\end{abstract}

\section{Keywords}

ARM, ZigBee, WSN, Agriculture Monitoring.

\section{INTRODUCTION}

The birth of agriculture and domestication of plants and animals was developed 10,000 years ago, in the change of time man realized the importance of agriculture. Comprehensive farming allowed food to much greater population as it reduced the hunting and gathering. Man learned techniques and new way for better farming in which weather forecasting plays major role. In order to predict the climatic changes instruments were needed to measure the soil moisture, temperature and humidity. The first invention of soil moisture sensor is Tensiometer and pressure membrane is used to measure the moisture in the soil in the year 1940, and thermometer to measure temperature in 1592 .

The potential economic benefits for accurate monitoring in agriculture are endless. Selective farming and harvesting times protects the crops from temperature and humidity rather than with more climatic monitoring, but to yield a better throughput and insure the protection of the crops agriculture monitoring leads the way.

The above reasons explain the advantage of agriculture monitoring. Agriculture monitoring system is designed in a portable way and easy to use which stores the sensed parameters for future analysis. For this ARM7 based 16/32-bit microcontroller LPC2148 whose core is a 32 bit embedded RISC processor which provides the best performance in power and area characteristics. The ARM7TDMI core empowers the embedded system designer to design a low power, small size and high performance devices. It has UART serial communication which allows us to design a ZigBee network, inbuilt analog to digital converters which can be directly interfaced to the sensors which have analog values. Soil moisture sensor, temperature and humidity sensor are used to measure the climatic parameters in agriculture land. LCD used to display the sensed parameters. The content of soil dryness, humidity and temperature values is displayed in a Graphical user interface (GUI). And the received values with respect to time and date are stored in the system data base, the GUI is designed using Visual Basic 6.0.
The below Table I gives the comparisons between present existing systems with ZigBee. First six features are important to be considered for the networking system. Here our aim is to implement a low power and low cost system with effective coverage and expendability, through Wi-Fi and latest WiMax we can increase the range and data rate but it increases the cost and usage of power in ZigBee we can expand the network with less usage of power and also cost effective. For implementing a network in medium range with low cost and low power ZigBee is suitable, for extreme long range monitoring WiMax and 802.11 s are considered.

Table I: Comparison between Wi-Fi, Bluetooth and ZigBee

\begin{tabular}{|l|l|l|l|}
\hline Features & Wi-Fi & Bluetooth & ZigBee \\
\hline Radio & DSSS & FHSS & DSSS \\
\hline Data rate & $11 \mathrm{Mbps}$ & $1 \mathrm{Mbps}$ & $250 \mathrm{kbps}$ \\
\hline $\begin{array}{l}\text { Nodes per } \\
\text { master }\end{array}$ & 32 & 7 & 64,000 \\
\hline $\begin{array}{l}\text { Slave } \\
\text { enumeration } \\
\text { latency }\end{array}$ & Upto 3 s & Upto 10 s & $30 \mathrm{~ms}$ \\
\hline $\begin{array}{l}\text { Data type } \\
\text { Audio, } \\
\text { graphics, } \\
\text { pictures, } \\
\text { files }\end{array}$ & $\begin{array}{l}\text { Audio, } \\
\text { praphics, } \\
\text { files }\end{array}$ & $\begin{array}{l}\text { Small } \\
\text { packets }\end{array}$ \\
\hline Range (m) & 100 & 10 & 70 \\
\hline Extendibility & $\begin{array}{l}\text { Roaming } \\
\text { possible }\end{array}$ & No & Yes \\
\hline Batter life & Hours & 1 week & $>1$ Year \\
\hline Complexity & Complex & $\begin{array}{l}\text { Very } \\
\text { complex }\end{array}$ & Simple \\
\hline
\end{tabular}




\section{BLOCK DIAGRAM}

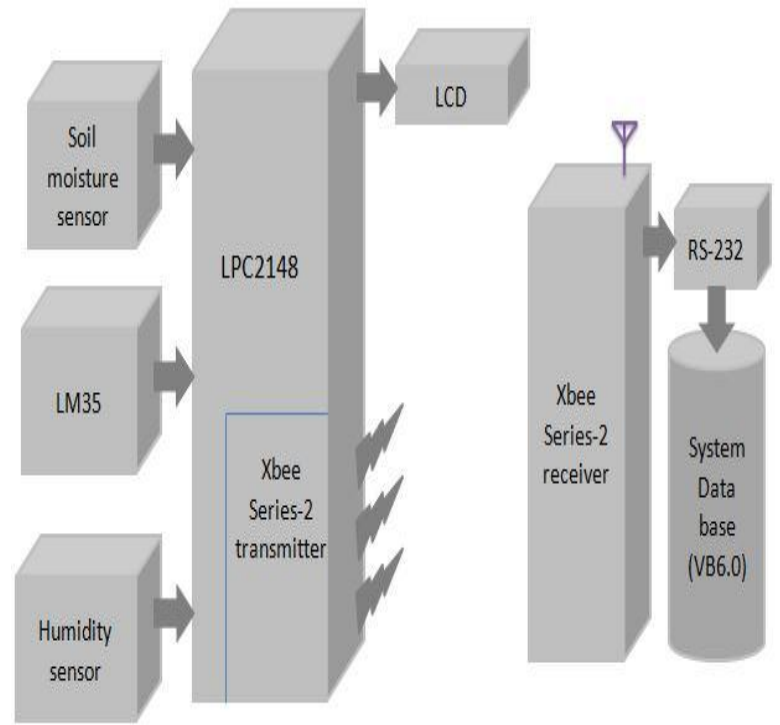

Fig. 1 Block Diagram of the Proposed System

\section{FEATURES OF}

\section{MICROCONTROLLER}

ARM7 LPC2148 has the following features which are required for monitoring agriculture environment [6]

1. 16/32- bit ARM7 TDMI-S microcontroller

2. In-system programming / In-Application programming (ISP/IAP)

3. $40 \mathrm{kB}$ of on-chip static RAM and $512 \mathrm{kB}$ of on-chip flash memory

4. Two 10-bit ADCs provide a total of 14 analog inputs, with conversion time as low as $2.44 \mu$ s per channel

5. Multiple serial interfaces including two UARTs

6. 48 of $5 \mathrm{~V}$ tolerant fast general purpose $\mathrm{I} / \mathrm{O}$ pins

7. CPU operating voltage range of $3.0 \mathrm{~V}$ to $3.6 \mathrm{~V}( \pm 10 \%)$ with $5 \mathrm{~V}$ tolerant $\mathrm{I} / \mathrm{O}$

\section{INTERFACING SENSORS TO MICROCONTROLLER}

Monitoring agriculture means sensing variation in the environmental. The basic parameters which are taken into consideration are soil moisture content, temperature and relative humidity. For this, temperature, humidity and soil moisture sensors are used.

\subsection{Soil Moisture Sensor}

Soil moisture is manufactured by iteadstudio. It is mainly used to detect the presence of moisture in the soil [7]. Soil moisture sensor gives the output in two different forms i.e. analog and digital. In digital mode the sensor reads the value and compares it with the threshold voltage, if the value is above threshold then it gives $0 \mathrm{~V}$ digital output. if the value read by the sensor is below the threshold voltage, a high output voltage of 3.3 or $5 \mathrm{~V}$ will be generated in this way we can directly read the current soil moisture if it is above threshold or not. In analog mode the accurate dryness of the soil is read in percentage. The pin connection and switching of modes is shown in the figure 2 . In order to have the exact percentage value sensor is activated in analog mode. The data pin is connected to the channel-2 of the inbuilt ADC using port pin P0.29.

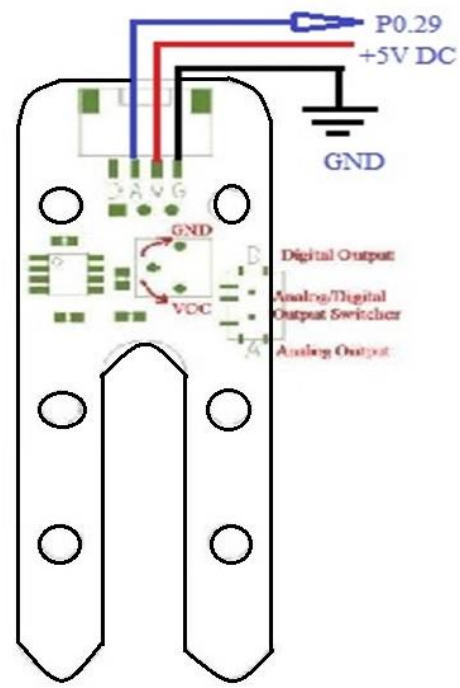

Fig. 2 Pin Connections of Soil Moisture Sensor

\subsection{Temperature and Humidity Sensor}

Temperature and humidity are important factors which influence growth of plants. A digital component manufactured by sunrom technologies is used to measure the temperature and relative humidity, the schematic diagram of the sensor shown in figure 3 . In the digital component LM35 IC which was manufactured by national Semiconductors is used to measure temperature and HS1101 is used to measure relative humidity. This sensor reads the temperature and humidity values and coverts to digital and outputs in simple serial interface of two types, Serial and SPI output. The sensors work on a $5 \mathrm{~V}$ DC supply, and supply current of $20 \mathrm{~mA}$. The operating temperature range of LM35 sensor is $60^{\circ} \mathrm{C}$. The accuracy of LM35 is $\pm 2^{\circ} \mathrm{C}$. Humidity value ranges from 1 to $100 \% \mathrm{RH}$. The accuracy of humidity sensor is $\pm 5 \% \mathrm{RH}$. The read values of the sensor are connected through the data line TXD output serial data is connected to the port pin of P0.9 as shown in figure 4.

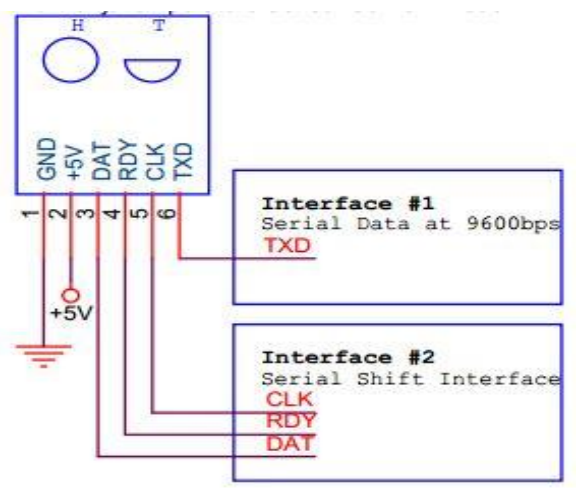

Fig. 3 Schematic diagram of temperature and humidity sensor 


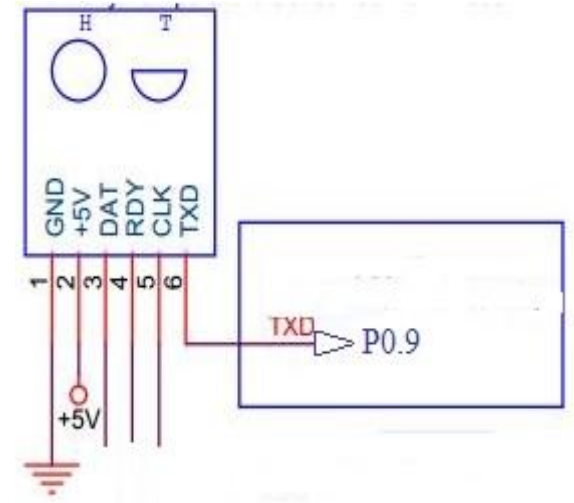

Fig. 4 Pin connections of temperature and humidity sensor to microcontroller

\section{ANALOG TO DIGITAL CONVERTER}

The analog to digital converter is in built in ARM7 LPC2148 microcontroller. The analog to digital converter is a 10 bit resolution with programmable acquisition of data. One channel out of 14 channels which are divided in ADC0 and $\mathrm{ADC} 1$ are used to take analog data from the soil moisture sensor. 10 bit data conversion time is $\geq 2.44 \mu$ s the sensed value from the sensor is converted to digital equivalent. The digital values are given to the microcontroller with a reference voltage of $3.1 \mathrm{~V}$. Used $\mathrm{ADC}$ register are ADDR2-A/D channel-2 Data Register.

\section{INTERFACING LCD TO MICROCONTROLLER}

A liquid crystal display (LCD) is a thin, flat panel used for electronically displaying information such as text and integers. Its major features are lightweight construction, and portability. The sensor values are displayed continuously on LCD. Four data lines are used to send data on the LCD. When $\mathrm{RS}=0$ and $\mathrm{EN}$ pin is made high to low command is sent to LCD. When RS=1 and EN pin is made high to low data is sent to $\mathrm{LCD}$. $\mathrm{V}_{\mathrm{EE}}$ is used to adjust contrast. The pin connections to microcontroller are shown in figure 5.

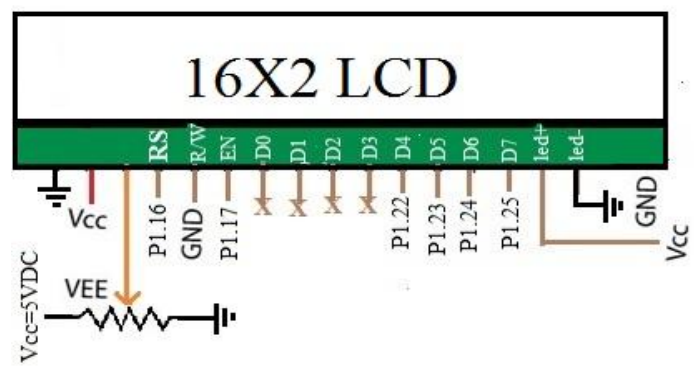

Fig. 5 Pin connections of LCD to LPC2148

\section{INTERFACING ZIGBEE TO MICROCONTROLLER}

Zigbee is wireless communication protocol for low power, low rate, reliable, and secured wireless personal area network, developed by ZigBee alliance based on IEEE 802.15.4 standards [10]. Zigbee network is supported by a multi-hop network in order to communicate with two devices they have to depend on other intermediate devices. In a ZigBee network there are three device types. (i) A Coordinator (ii) router and (iii) end device. A network consists of a coordinator node and multiple router and end device nodes. Before establishing a network Xbee modules are first configured using X-CTU software one as a coordinator and others as routers. An Xbee series 2 is shown in figure 6. Pin 2 of Xbee is interfaced to the microcontroller to port pin $\mathrm{P} 0.1$ from which the data is transmitted.

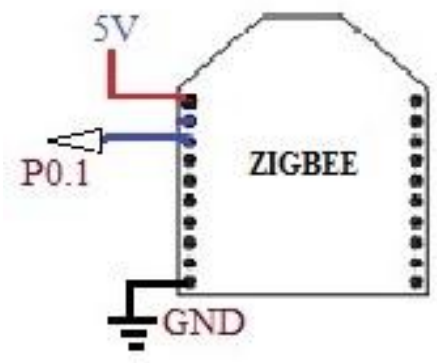

Fig. 6 Pin connections of Zigbee to Microcontroller

\section{INTERFACING ZIGBEE TO PC}

Xbee modules are mounted on Xbee development Kits contain RS-232 interface boards which is shown in figure 7.

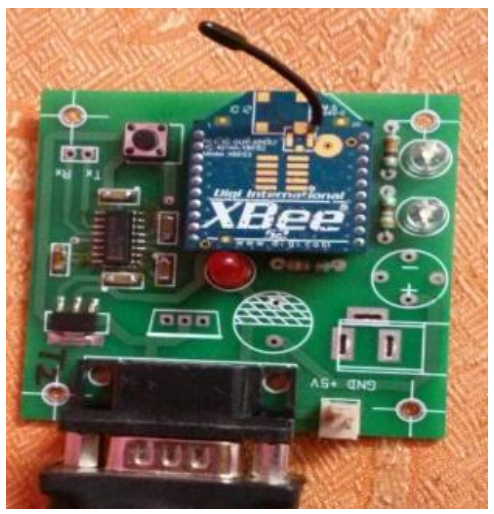

Fig. 7 Xbee interfacing to PC through development kit

\section{SOFTWARE USED}

1. For programming keil $\mu 4$ and for dumping the code flash magic are used.

2. For configuring Xbee modules X-CTU software is used.

3. GUI is designed using Visual Basic 6.0 for user interface and data base

\section{VISUAL BASIC 6.0}

Graphical user interface (GUI) is designed for easy user interface and storing of the received values using RS-232 serial communication. The GUI is programmed to update the received parameters for every $5 \mathrm{~s}$ interval and store the data in MS-Access database, and the received parameters are shown in GUI and updated for every $10 \mathrm{~s}$ interval. For Maintaining ZigBee communication without congestion a $10 \mathrm{~s}$ interval is taken. GUI is shown in figure 8 . The Xbee module which is connected to the system through RS-232 and the com port is selected and then system is started and received values are shown and are stored in the system. 


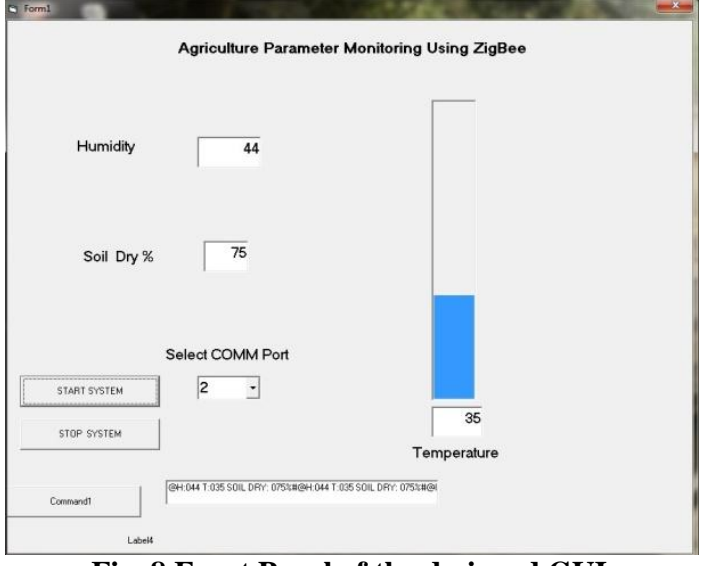

Fig. 8 Front Panel of the designed GUI

\section{RESULTS AND CONCLUSION}

Sensors and ZigBee are interfaced to microcontroller. The sensed parameters are displayed on LCD display. The received parameters are continuously displayed on graphical user interface and the data and time of each value is stored in system database, the below table II shows the results stored in Micro Soft Access Database. Hence, the project agriculture monitoring is designed and developed using ARM. The developed system is successful in measuring the dryness of the soil, relative humidity and temperature. The values received values which are stored in system database are used for further analysis.

\section{Table II: received Sensor Values with Time and Date}

\begin{tabular}{|c|c|c|c|}
\hline \multicolumn{4}{|c|}{ Monitor } \\
\hline Date_Time & Humidity & $\begin{array}{c}\text { Temperatur } \\
\mathrm{e}\end{array}$ & SoilDry \\
\hline $\begin{array}{l}\text { 20-11-2013 } \\
\text { 4:48:49 PM }\end{array}$ & 39 & 30 & 56 \\
\hline $\begin{array}{l}20-11-2013 \\
4: 48: 54 \text { PM }\end{array}$ & 38 & 30 & 63 \\
\hline $\begin{array}{l}20-11-2013 \\
\text { 4:48:59 PM }\end{array}$ & 37 & 31 & 82 \\
\hline $\begin{array}{l}\text { 20-11-2013 } \\
\text { 4:49:04 PM }\end{array}$ & 37 & 31 & 68 \\
\hline $\begin{array}{l}\text { 20-11-2013 } \\
\text { 4:49:09 PM }\end{array}$ & 37 & 32 & 57 \\
\hline $\begin{array}{l}\text { 20-11-2013 } \\
\text { 4:49:14 PM }\end{array}$ & 37 & 32 & 73 \\
\hline $\begin{array}{l}20-11-2013 \\
4: 49: 19 \text { PM }\end{array}$ & 36 & 33 & 60 \\
\hline $\begin{array}{l}\text { 20-11-2013 } \\
\text { 4:49:24 PM }\end{array}$ & 36 & 33 & 60 \\
\hline $\begin{array}{l}\text { 20-11-2013 } \\
\text { 4:49:29 PM }\end{array}$ & 36 & 34 & 60 \\
\hline $\begin{array}{l}\text { 20-11-2013 } \\
\text { 4:49:34 PM }\end{array}$ & 38 & 34 & 60 \\
\hline $\begin{array}{l}\text { 20-11-2013 } \\
\text { 4:49:39 PM } \\
\end{array}$ & 36 & 34 & 60 \\
\hline $\begin{array}{l}20-11-2013 \\
4: 49: 44 \text { PM }\end{array}$ & 38 & 35 & 61 \\
\hline $\begin{array}{l}20-11-2013 \\
4: 49: 50 \mathrm{PM}\end{array}$ & 40 & 35 & 61 \\
\hline $\begin{array}{l}20-11-2013 \\
4: 49: 55 \text { PM }\end{array}$ & 37 & 36 & 60 \\
\hline
\end{tabular}

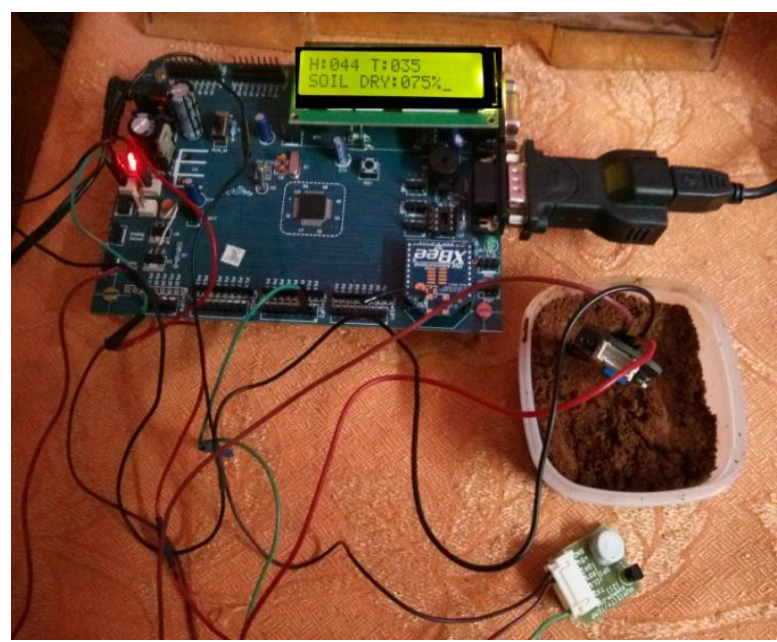

Fig. 9 Overall view of implemented system

\section{REFERENCES}

[1] Gerard Rudolph Mendez, Mohd Amri Md Yunus and Subhas Chandra Mukhopadhya, "A WIFI based Smart Wireless Sensor Network for Monitoring an Agriculture Environment". Instrumentation and Measurement Technology Conference(I2MTC), 2012 IEEE International

[2] Prakashgoud Patil, Umakant Kulkarni, "Wireless Sensor Network for Precision Agriculture", 2011 international conference on Computational Intelligence and communication networks (CICN).

[3] T.Kalaivani, P.Priya,A.Allirani, "A Survey on Zigbee based Wireless Sensor Networks in Agriculture", 2011 $3^{\text {rd }}$ international conference on Trendz in Information Science and computing (TISC)

[4] Luca Bencini, Francesco Chiti, Giovanni Collodi, Davide Di Palma, Romano Fantacci, Antonio Manes, Gianfranco Manes, "Agriculture Monitoring based on Wireless Sensor Network Technology: real long life deployments for physiology and pathogens control”, 2009 third international conference on Sensor Technologies and Applications.

[5] A.I.Johnson, "Methods of Measuring Soil Moisture in the Field", Geological Survey Water-Supply paper 1619U.

[6] LPC2148X, User-manual,

www.nxp.com/documents/user_manual/UM10139.pdf

[7] Soil Moisture Sensor, User-Manual,

http://imall.iteadstudio.com/Electronic_Brick/IM121017001/ DS_IM121017001.pdf

[8] Temperature and Humidity Sensor, datasheet,

www.sunrom.com/media/files/p/224/1211-datasheet.pdf

[9] Faheem Ijaz, Adeel A. Siddiqui , Byung K wan Im , CHankil Lee, "Remote Management and control system for LED based Plant Factory using ZigBee and Internet". $201214^{\text {th }}$ International Conference on Advanced Communication Technology (ICACT).

[10] ZigBee datasheet,

www.digi.com/support/documentation/90000866_A.pdf 